\title{
Spatial and temporal dynamics of epileptic activity at sleep onset in the Encephalopathy with Status Epilepticus during slow sleep (ESES) after unilateral thalamic lesions
}

\author{
Alberto Leal* \\ Clinical Neurophysiology Lab, Centro Hospitalar Psiquiátrico de Lisboa, Lisbon, Portugal \\ EEG Lab - Pediatric Neurology Department, Hospital Dona Estefânia, Lisbon, Portugal
}

\section{A R T I C L E I N F O}

\section{Article history:}

Accepted 6 November 2020

Available online 17 November 2020

\section{Keywords:}

ESES

CSWS

Epilepsy

Source analysis

Thalamus

Connectivity

\section{H I G H L I G H T S}

- ESES is associated with multifocal spike activity, rendering difficult the analysis of brain areas involved in its genesis.

- EEG at sleep onset in 5 ESES patients demonstrated focal cortical generators and widespread secondary propagation.

- ESES originate focally in hemisphere with unilateral thalamic lesion, supporting a causal anatomicalphysiological dysfunction relationship.

\begin{abstract}
A B S T R A C T
Objective: Encephalopathy with Status Epilepticus during slow Sleep (ESES) is a syndrome where neurocognitive impairment correlates with multifocal Electroencephalography (EEG) spikes increasing abruptly at sleep onset. Demonstration of a focal onset could provide important clues to unravel the mechanisms underlying the condition, but until know it has not been established.

Methods: We studied epileptic dynamics at sleep onset to assess its focal or diffuse features in five patients with perinatal thalamic hemorrhages lateralized to one hemisphere, using high resolution EEG. Results: Dynamical functional connectivity revealed the information flow in the epileptic network and identified primary sources of outflow, equated with cortical spike sources. We found that spikes with important activation originate in restricted cortical areas of the hemisphere with the lesion, spreading widely and quickly at onset of N2 sleep stage.

Conclusions: Perinatal thalamic lesions have the potential to induce, years later, a regional onset of epileptic activity with features of ESES in a cortex without apparent structural lesion. Most widespread spike activity in the scalp results from secondary propagation.

Significance: Perinatal thalamic lesions produce ESES with focal onset in a restricted cortical area of the hemisphere with the lesion, and prominent secondary propagation.
\end{abstract}

(c) 2020 International Federation of Clinical Neurophysiology. Published by Elsevier B.V. All rights reserved.

\section{Introduction}

The Encephalopathy with Status Epilepticus during slow Sleep (ESES) is a neurological condition of the pediatric age where a strong activation of interictal spikes occurs in relation with nonRapid Eye Movements (non-REM) sleep in an otherwise

* At: Unidade Autónoma de Neurofisiologia, Centro Hospitalar Psiquiátrico de Lisboa, Avenida do Brasil 53, 1740-002 Lisboa, Portugal.

E-mail address: albertoleal@chpl.min-saude.pt unremarkable epilepsy (Tassinari et al, 1977). Neurocognitive dysfunction and behavioral disturbances are common and have been attributed to the peculiar interictal activity (Dorris et al, 2019). The syndrome runs a self-limited course, with onset in the first years of life and resolution by adolescence, but neuropsychological sequela can persist (Caraballo et al, 2019).

The very abundant and sleep state-dependent interictal activity (Nobili et al, 2001) is a distinctive feature of the syndrome and it has generated a lot of interest in trying to understand its neuronal basis and the correlation with the significant impact on 
neurocognitive performance (Gibbs et al, 2019). Unfortunately, no mechanism has been firmly established that can explain the core neurophysiological manifestations of the epileptic activity in ESES, and so the underpins of the relationship with sleep and cognition remain speculative. Several factors make this endeavor a difficult one: a) A wide range of different etiologies can lead to ESES, and none shows a clear numeric dominance (Fernandez et al, 2012); b) ESES can occur with or without structural lesions and no particular brain area has shown a consistent relationship with the syndrome, despite the progressive interest in thalamic lesions and the perisylvian cortex (Siniatchkin et al, 2010; Gibbs et al., 2019); c) In most cases spike activity is multifocal and no consistent brain generator has been established (Halász et al, 2014; Caraballo et al, 2015); d) Response to conventional antiepileptic drugs is poor (Van den Munckhof et al, 2015), suggesting that a distinct mechanism from the one present in other epileptic syndromes is at work, a distinction which is also supported by the good response to corticosteroids (Carvalho et al, 2020).

Among the diverse etiologies one has emerged in recent years as having promising features to highlight the mechanisms of ESES, the perinatal thalamic hemorrhages. These rare and often dramatic conditions produce well-defined structural lesion (most commonly in a single hemisphere) on an otherwise well-structured brain, which in most cases is followed by a significant recovery of neurological developmental milestones (Monteiro et al, 2001; Kelemen et al, 2006; Kersbergen et al, 2013). A recent prospective series of these patients (Van den Munckhof et al, 2020) has demonstrated that the large majority ( $>80 \%$ ) evolve to ESES years later, making this the etiology with the highest predictability of evolution to the syndrome, and supporting a causal relationship. We have previously provided evidence to support a decrease in structural thalamic-cortical connectivity of the hemisphere with the lesion (Leal et al, 2018) and, in a more recent study, demonstrated that thalamic lesions induce regional white matter atrophy which is associated both with brain dysfunction and the localization of generators of ESES spike activity (Oliveira et al, 2020). These data support the interpretation that a thalamic lesion can induce years later a regional cortical epileptic focus with the features described in ESES, the localization of which seems to be influenced by the anatomical details of the thalamic-cortical disconnection.

In the present paper we study in more detail the spatial and temporal dynamics of spike activity at the critical transition between wakefulness and non-REM sleep in ESES, with the following main goals: 1) Identify the cortical areas activating at sleep onset in an individual basis; 2) Make use of dynamic connectivity models of spike activity to establish the information flow and discriminate areas of onset and propagation; 3) Determine the epileptogenic potential of the hemisphere with the thalamic lesion compared to the contralateral one.

\section{Material and methods}

\subsection{Clinical data}

A sample of 8 patients with the diagnosis of ESES associated with a neonatal or prenatal vascular lesion restricted to one thalamus were selected for the study and submitted to a highresolution Electroencephalogram (EEG), (Fig. 1a), including wakefulness and sleep. One patient was excluded from further analysis because it was not possible to record sleep. Clinical and neurophysiological features of the remaining group are shown in Table 1. This sample is part of a larger group of patients followed at our clinical neurophysiology lab for several years with diverse modalities, including repeated $24 \mathrm{~h}$ ambulatory EEGs and neuropsychological assessments. Partial results of this effort have resulted in several publications (Leal et al, 2018, Carvalho et al, 2020; Oliveira et al, 2020).

In five patients a hemorrhagic thalamic stroke occurred in the neonatal period, while for the remaining two thalamic lesions were a finding in the brain Magnetic Resonance Imaging (MRI) performed as part of epilepsy assessment, (Fig. 2). In all cases some degree of cognitive/behavioral regression followed the onset of epilepsy, (Table 1), but in all except one case (P1) seizures were sporadic and responsive to antiepileptic drugs. The quantification of interictal activity revealed Spike Indexes (SI) higher than $85 \%$ of the non-REM sleep in whole-night EEG recordings (Leal et al, 2018; Carvalho et al, 2020).

The study was approved by the local ethics committee and all data acquisitions were obtained as part of the clinical investigation of the patients condition.

\subsection{EEG recordings and processing}

\subsubsection{EEG recording and pre-processing}

A 1-2-hour EEG record including wake and sleep periods was obtained from each patient at rest, using a set of 82 channels (full 10-10 system plus F11/12, FT11/12, TP11/12, P11/12, referenced to $\mathrm{FCz}$ ), in the afternoon period. Ring electrodes of sintered $\mathrm{AgCl}$ (EasyCap) applied in an elastic cap, were connected to a medical grade Digital Electroencephalograph (SynAmps 2, CompumedicsNeuroscan) running the Scan 4.5 software. The sampling rate was $1000 \mathrm{~Hz}$, filters DC-70 Hz (notch $50 \mathrm{~Hz}$ ) and the impedance remained below $5 \mathrm{kOhm}$ throughout acquisition. The 3D position of the electrodes and head landmarks was obtained with a Polhemus Patriot electromagnetic digitizer.

The raw EEG was imported to the EEGLAB toolbox running in MatLab 7.10 (R2010a), high pass filtered at $0.5 \mathrm{~Hz}$ and visually inspected for large EMG or movement artifacts, whose epochs were marked and removed from the recording. Eye movement channels were obtained from F9-FT12 and F10-FT11 derivations. The record was also exported to EDF format and imported to the software ProFusion PSG5.0 (Compumedics-Neuroscan) for sleep staging, using the AASM (American Academy of Sleep Medicine) rules, without chin Electromyography (EMG).

\subsubsection{Decomposition in Independent Components (IC) and selection of spike-related ones}

The EEG was processed through a pipeline including (Fig. 1a): decomposition in Independent Components (ICs) using the runica algorithm implemented in EEGLAB (v2019.1); removal of ICs visually identified with artifacts; decomposition in ICs of the artifactfree EEG; split of the record into wake and sleep epochs; visual identification and manual tag of different spike types; spike average of each type in wake and sleep epochs.

For each spike type the highest amplitude of the 82 ICs set was chosen and correlated with all the others using the non-linear h2 metrics (Pijn et al, 1989). We calculated the noise (Root Mean Square) of the average spikes before the peak $(-100$ to $-60 \mathrm{~ms})$ for all patients and found that it was consistently below $7.5 \%$ of the spike peak amplitude. The ICs with an amplitude threshold twice the maximal noise level (15\%) and a h2 higher than $80 \%$ were accepted as spike-related, while the remaining ones were tagged as non-spike-related, (Fig. 1b), and excluded from further analysis. The total number of spike-related ICs was calculated for each wake and sleep epochs, (Fig. 1c), and the total number of spike types visually assessed by the author was recorded, (Fig. 1d).

\subsubsection{Functional connectivity and selection of leading ICS}

For each spike type the cortical source of each spike-related IC was calculated using methods described in section 2.3 and its aver- 

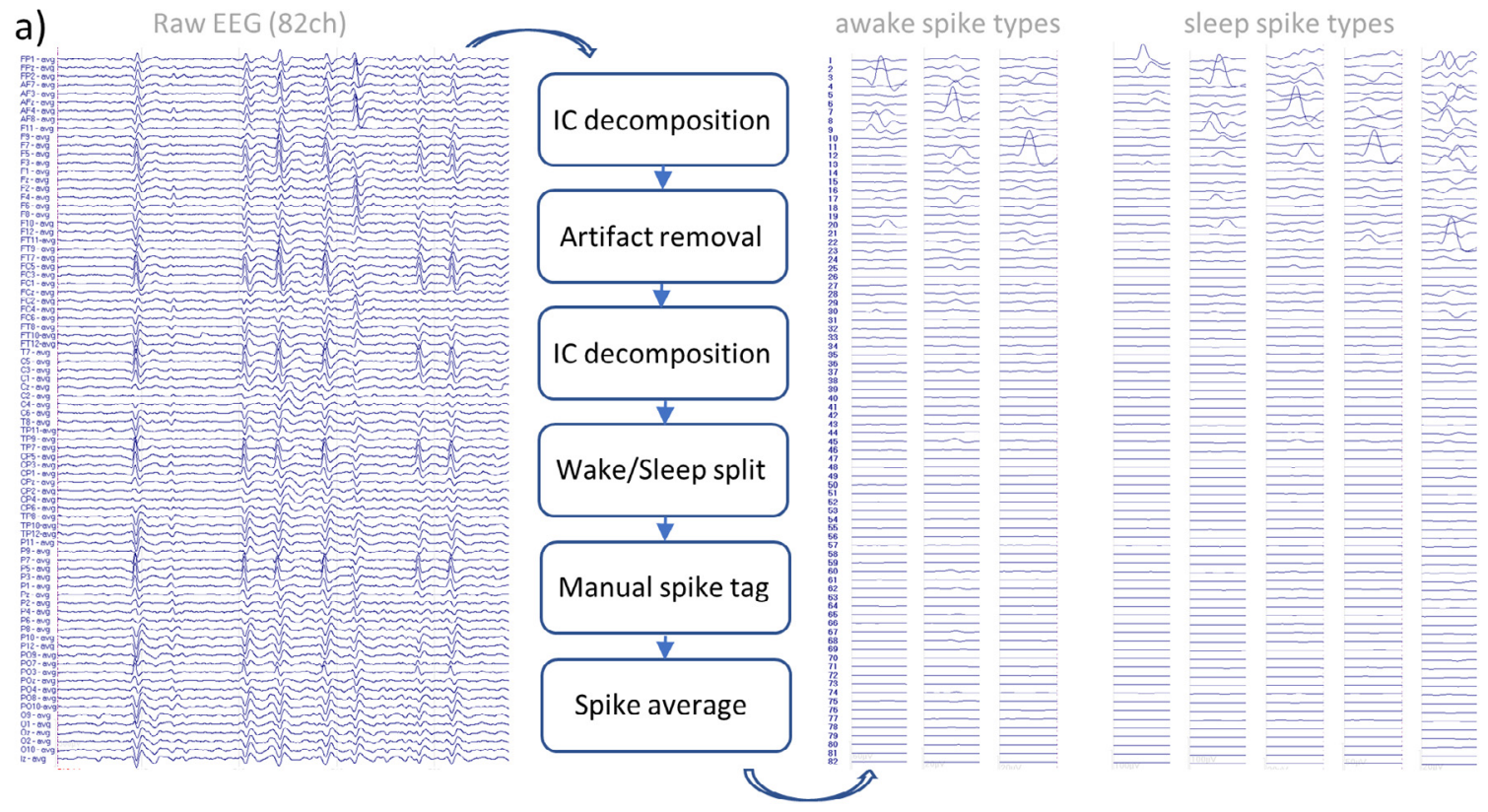

b)

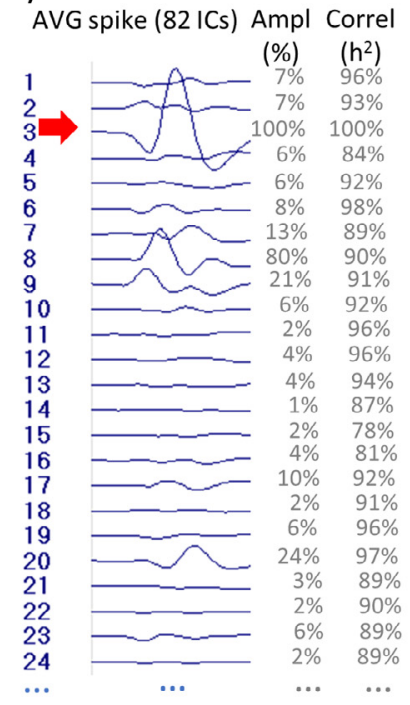

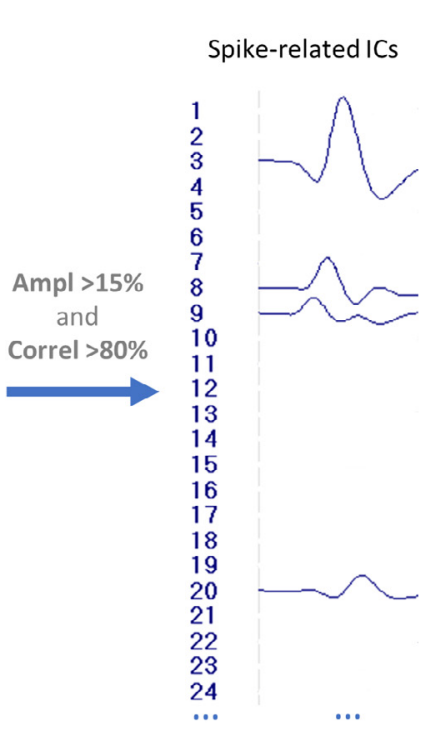

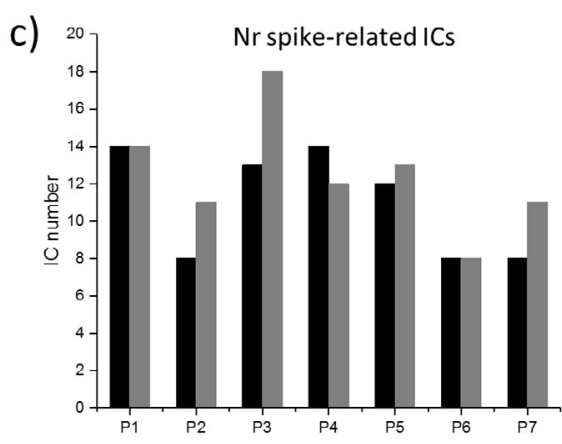

d)

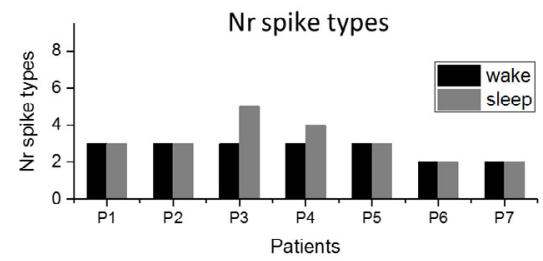

e)

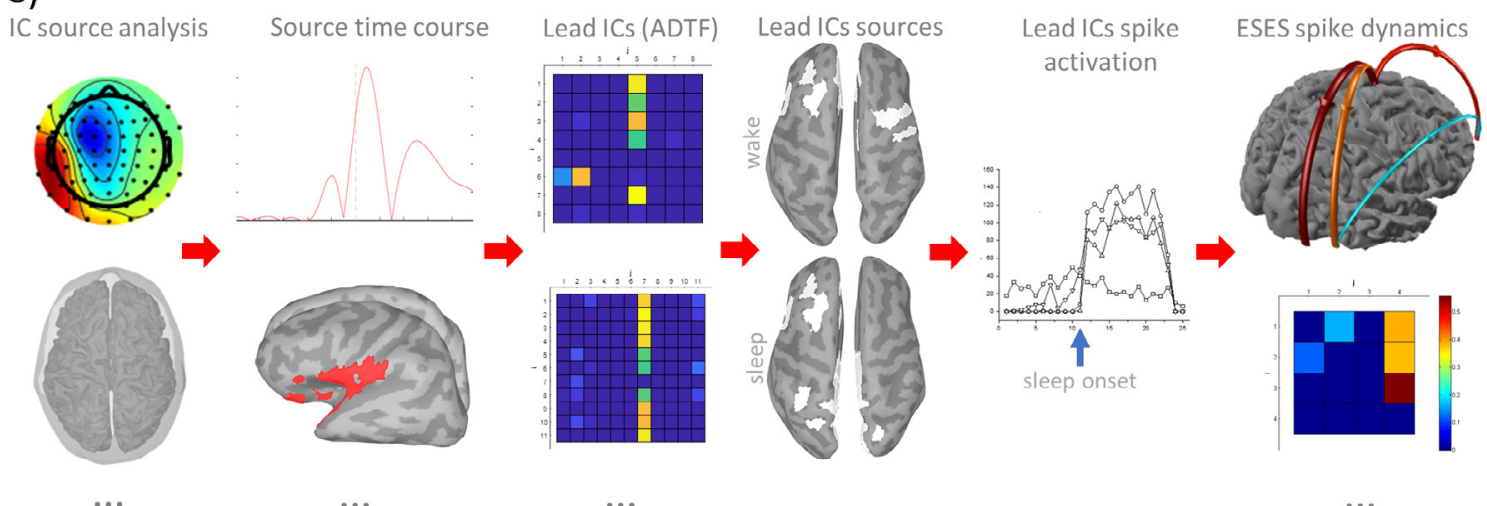

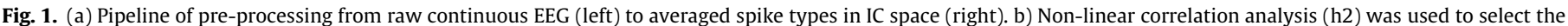

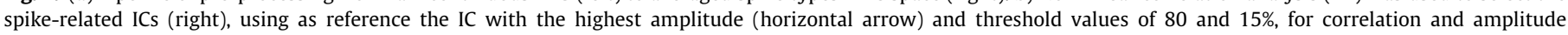

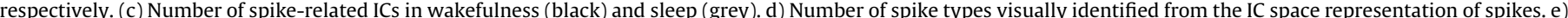

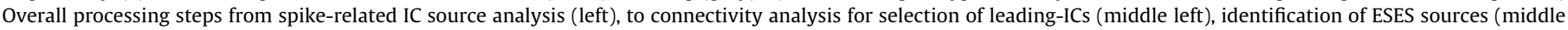

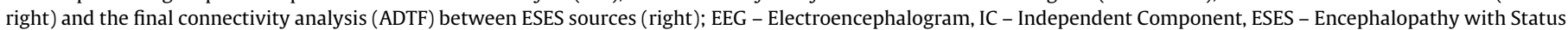
Epilepticus during slow Sleep, ADTF - Adaptative Direct Transfer Function. 
Table 1

Clinical, Behavioral and Neurologic data.

\begin{tabular}{|c|c|c|c|c|c|c|c|}
\hline & P1 & P2 & P3 & P4 & P5 & P6 & P7 \\
\hline Age at EEG assessment & $5 \mathrm{y} 10 \mathrm{~m}$ & $9 y 6 m$ & $10 y$ & $9 y$ & $10 \mathrm{y}$ & $15 y$ & $12 \mathrm{y}$ \\
\hline Age at Epilepsy onset & $2 \mathrm{y}$ & $1 \mathrm{y}$ & $5 y$ & $2 \mathrm{y}$ & $2 y$ & $6 y$ & $5 y$ \\
\hline Thalamic lesion & Left & Right & Left & Right & Right & Left & Left \\
\hline Etiology & $\begin{array}{l}\text { Neonatal } \\
\text { hemorrhage }\end{array}$ & $\begin{array}{l}\text { Neonatal } \\
\text { hemorrhage }\end{array}$ & $\begin{array}{l}\text { Pre-natal } \\
\text { hemorrhage }\end{array}$ & $\begin{array}{l}\text { Neonatal } \\
\text { hemorrhage }\end{array}$ & $\begin{array}{l}\text { Pre-natal } \\
\text { hemorrhage }\end{array}$ & $\begin{array}{l}\text { Neonatal } \\
\text { hemorrhage }\end{array}$ & $\begin{array}{l}\text { Neonatal } \\
\text { hemorrhage }\end{array}$ \\
\hline Current AEs & & VPA, LVT, CBZ & $\begin{array}{l}\text { Ketogenic diet, } \\
\text { VPA, DPH }\end{array}$ & VPA, LMT & Prednisolone & LVT & LVT \\
\hline Cognitive status & $\begin{array}{l}\text { Severe learning } \\
\text { disability }\end{array}$ & $\begin{array}{l}\text { Language and } \\
\text { drawing skills } \\
\text { regression at } \\
\text { age } 3 y\end{array}$ & $\begin{array}{l}\text { Scholar regression } \\
\text { from } 7-8 y\end{array}$ & $\begin{array}{l}\text { Regression with } \\
\text { visual and } \\
\text { visuo-spatial } \\
\text { impairments }\end{array}$ & $\begin{array}{l}\text { Severe learning } \\
\text { problems }\end{array}$ & $\begin{array}{l}\text { Severe learning } \\
\text { problems }\end{array}$ & $\begin{array}{l}\text { Learning } \\
\text { dificulties }\end{array}$ \\
\hline Neurological status & $\begin{array}{l}\text { Severe spatial } \\
\text { disorientation }\end{array}$ & $\begin{array}{l}\text { Spatial } \\
\text { desorientation } \\
\text { and } \\
\text { atentional } \\
\text { impairment }\end{array}$ & $\begin{array}{l}\text { Severe spatial } \\
\text { disorientation }\end{array}$ & $\begin{array}{l}\text { Spatial } \\
\text { desorientation }\end{array}$ & Normal & & Normal \\
\hline Behavioral status & $\begin{array}{l}\text { Uncooperative, } \\
\text { lack of } \\
\text { concentration }\end{array}$ & $\begin{array}{l}\text { General slowing } \\
\text { and lack of } \\
\text { interest }\end{array}$ & $\begin{array}{l}\text { General slowing } \\
\text { and poor planing }\end{array}$ & Normal & $\begin{array}{l}\text { Lack of } \\
\text { concentration, } \\
\text { uncooperative, } \\
\text { agitated }\end{array}$ & $\begin{array}{l}\text { General slowing, } \\
\text { poor planning }\end{array}$ & $\begin{array}{l}\text { Uncooperative } \\
\text { behavior }\end{array}$ \\
\hline Formal assessment: & $4 y 9 m$ & $9 y$ & $9 y$ & $7 y$ & $7 \mathrm{y}$ & $14 y$ & $7 y$ \\
\hline CNAB & & $\begin{array}{l}\text { Not able to } \\
\text { cooperate }\end{array}$ & $\begin{array}{l}\text { Language, } \\
\text { Atention and } \\
\text { visual-spatial } \\
\text { impairment }\end{array}$ & & $\begin{array}{l}\text { Atentional, visual- } \\
\text { spatial and } \\
\text { spatial orientation } \\
\text { impairments }\end{array}$ & $\begin{array}{l}\text { Atentional, } \\
\text { executive function, } \\
\text { verbal } \\
\text { and working } \\
\text { memory } \\
\text { impairments }\end{array}$ & \\
\hline WISC-III & & $\begin{array}{l}\text { Not able to } \\
\text { cooperate }\end{array}$ & & $\begin{array}{l}\text { (IQ 74, vIQ 70, } \\
\text { pIQ 78) }\end{array}$ & IQ 60 & IQ 57 & $\begin{array}{l}\text { (IQ 71, vIQ 92, } \\
\text { pIQ 64) }\end{array}$ \\
\hline Griffiths & QG 87 & & & & & & \\
\hline $\begin{array}{r}\text { Early develop } \\
\text { milestones }\end{array}$ & $\begin{array}{l}\text { Delayed } \\
\text { walking (16 m), } \\
\text { normal speech }\end{array}$ & $\begin{array}{l}\text { Normal } \\
\text { (walking and } \\
\text { speach) }\end{array}$ & $\begin{array}{l}\text { Normal (walking } \\
\text { and speach) }\end{array}$ & $\begin{array}{l}\text { Normal } \\
\text { (walking and } \\
\text { speach) }\end{array}$ & $\begin{array}{l}\text { Normal (walking } \\
\text { and speach) }\end{array}$ & $\begin{array}{l}\text { Delayed walking } \\
(24 \mathrm{~m}) \text { and } \\
\text { speaking }(30 \mathrm{~m})\end{array}$ & $\begin{array}{l}\text { Normal } \\
\text { (walking and } \\
\text { speach) }\end{array}$ \\
\hline
\end{tabular}

CNAB (Coimbra Neuropsychological Assessment Battery); WISC-III (Wechsler Inteligence Scale for Children - 3rd ed); Griffiths (Griffith Mental Development Scale).
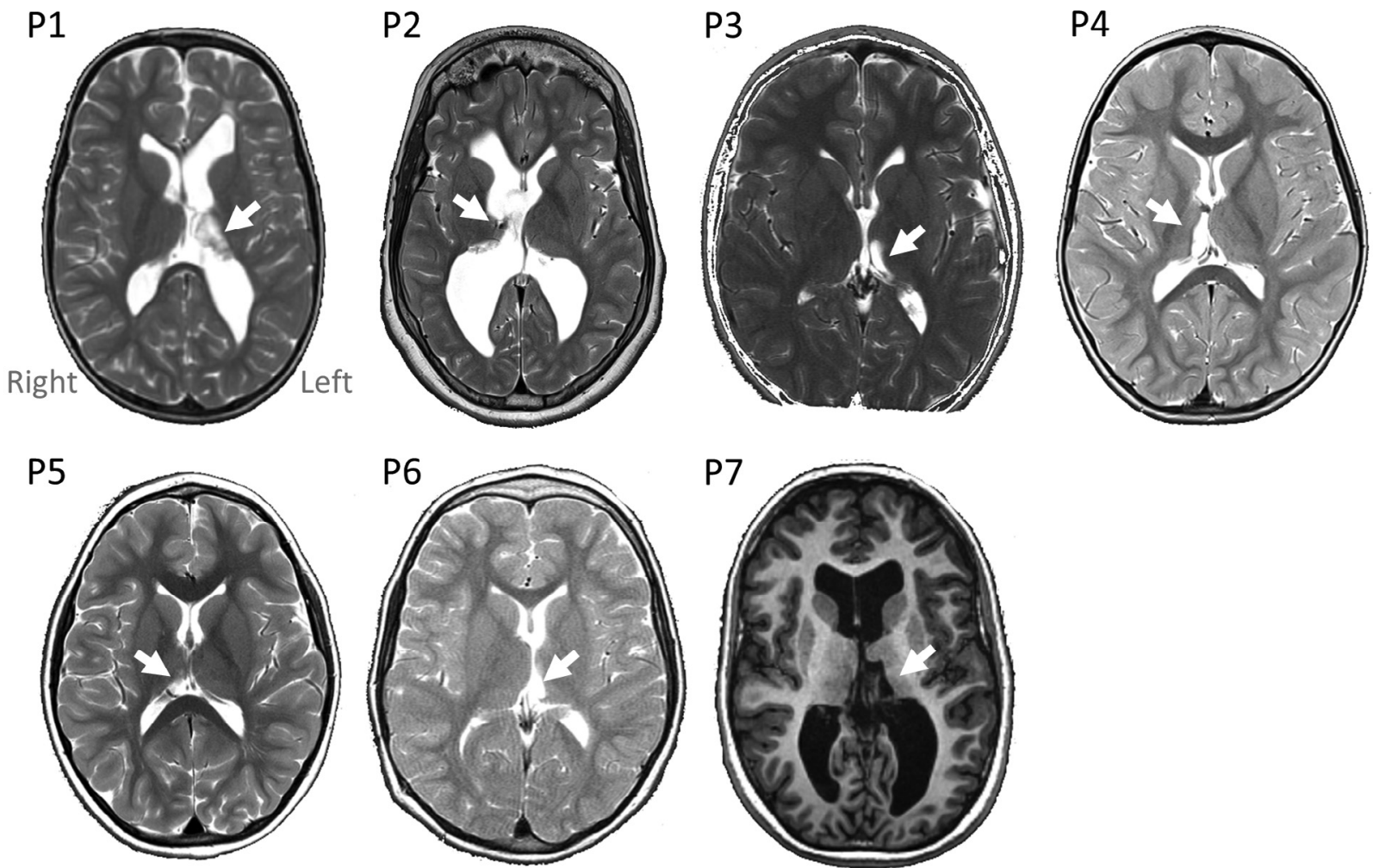

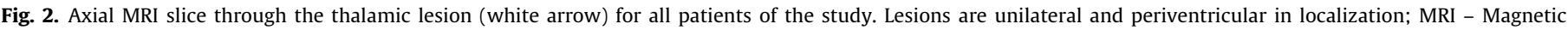
Resonance Imaging. 
age time-course recovered using the BrainStorm toolbox (Tadel et al, 2011), running in MatLab 9.7.0.

The functional connectivity at the spike peak between the cortical sources of spike-related ICs was calculated using the Adaptative Direct Transfer Function (ADTF), (Wilke et al, 2008), as implemented in the toolbox E-Connectome2.0 (He et al, 2011) running in MatLab 7.10. The statistical significance of the connectivity was assessed through a permutation test of 1000 samples and a $\mathrm{p}<0.05$.

The spike-related ICs with significant information outflow to other ICs but receiving little or no inflow from them were selected as leading-ICs and interpreted as cortical generators of spike activity, while the remaining ICs were considered secondary cortical generators resulting from spike propagation, (Fig. 3a).

\subsubsection{Quantification of leading IC spikes from wakefulness to sleep}

We extracted a 25-minute continuous sample of EEG per patient, including the transition from wakefulness to sleep, and selected the leading-ICs channels for spike identification. We run a template match algorithm to detect occurrences of a visually selected template spike, independently for each leading-IC, (Fig. 4a). The spike frequency (spikes/min) was quantified, (Fig. 1e). We also quantified the Mean Global Field Power (MGFP) from wake and sleep epochs, (Fig. 5b).

\subsubsection{Functional connectivity of leading IC sources}

The leading-ICs which more than doubled the spike frequency at sleep onset were considered ESES-related leading-ICs. The average spike of each ESES-related leading-IC was obtained. For each distinct cortical area with an ESES-related source, (Fig. 4, right column), a representative average spike was selected to assess the information flow at half-peak and peak, between all leading-ICs, (Fig. 6a). The overall ESES was classified as focal if a single, or adjacent cortical regions, were the main sources of outflow for the distinct spikes. The ESES was classified as multifocal if two or more non-adjacent cortical areas were the main flow of information for distinct spikes.

\subsection{MRI processing and source analysis}

Detailed anatomical head models were obtained from the volumetric T1 MRI sequences from all patients. The MRI was imported to the FreeSurfer software (Fischl et al, 2004) and the automatic processing pipeline of brain segmentation and partition was run, producing surface representations of the scalp, outer and inner skull, and of the cortical surface. These were used to create Boundary Element Models (BEM) using the OpenMEEG software (Gramfort et al, 2010) running in the BrainStorm toolbox. The source algorithm used was the cortical sLORETA with unconstrained sources restricted to the cortex.

\section{Results}

\subsection{Clinical features}

Five of the seven patients with the diagnosis of ESES included in the study demonstrated significant spike activation with sleep onset (aESES) at the time of assessment while the remaining two (iESES) no longer had such activation at that time, (Table 1). The iESES patients were older (12 and 15 years) than the aESES ones (5 to 10 years), in line with the well-known spontaneous regression of the condition by adolescence (Caraballo et al, 2019). All patients had clinical (P1, P2, P4, P6 and P7) or imaging (hemosiderin in the MRI, P3 and P5) evidence for a thalamic hemorrhage early in life, (Fig. 2). Most recovered well from this event to reach the normal milestones for walking and speech, but two (P1 and P6) were delayed in those acquisitions. All patients exhibited cognitive/behavioral impairment after epilepsy onset with severe impact on school performance and in daily interaction with infants of similar age, (Table 1), which is a defining manifestation of the ESES syndrome (Tassinari and Rubboli, 2019).

\subsection{Changes in spike-related independent components from wakefulness to sleep}

The visual inspection of the raw EEGs revealed the existence of apparently multifocal spikes with distribution over many electrodes, corresponding to widespread fields covering most of the 82-electrode array (Fig. 1a, left), which appeared much more diffuse in a typical 10-20 montage (supplementary Figure). The use of decomposition in ICs significantly reduced the overlapping and restricted the number of spike-related ICs as compared with the number of spike-related electrodes (Fig. 1a, right). For the aESES patients this number ranged from 8 to 14 while awake and from 11 to 18 in sleep. The two patients with iESES had 8 and $8-11$ respectively (Fig. $1 \mathrm{c}$ ).

The visual selection of spike types with distinct topography by a clinical neurophysiologist (AL) led to the identification of 2 to 5 spike types per patient, with a trend for a higher number in sleep (Fig. 1d).

Overall, the use of IC analysis allows a significant reduction on the number of channels required for representing spikes and makes easier the task of visually distinguish the diverse spike types. It also makes apparent that the increase in number of spike-related ICs and spike types from wakefulness to sleep is a modest one.

\subsection{Identification of leading cortical sources for diverse spike types}

Most spike-related ICs demonstrate a dipolar field which produces well defined sources with the use of the cortical SLORETA algorithm, (Fig. 3a). The functional connectivity analysis at the peak of spikes puts in evidence that only a limited number of ICs act as outflow sources, for each spike type (Fig. 3a). These leading-ICs receive little or no flow from other areas and express the characteristics expected for primary generators of epileptic activity.

The two iESES patients have a single leading-IC per spike type and their cortical sources remain stable from wakefulness to sleep, supporting the existence of a single epileptogenic area over the right occipital pole (Fig. 3a, above).

The aESES patients demonstrate a higher number of leading-ICs with widely separated cortical localizations (Fig. 3a, below), as compared with the iESES ones. Comparing localizations between wakefulness and sleep it is possible to find consistent areas of overlap: Patient P1 presents clustering of sources over the frontal lobes, which is lateralized to the left hemisphere in sleep; Patient P3 presents left hemisphere sources both in the frontal and inferior temporal areas, in wakefulness and sleep; P2 presents frontal lobe sources near the middle line in wakefulness and sleep and also inferior right temporal sources in the latte condition; P4 presents bilateral frontal sources in wakefulness and in sleep a left frontal and several middle line parietal sources; patient P5, the only patient undergoing treatment with corticosteroids, showed a stable pattern of sources, over the right posterior parietaloccipital areas, from wakefulness to sleep (Fig. 3a, below).

The analysis of the spike-related IC sources distribution by hemisphere, (Fig. 3b), reveals a modest asymmetry, with preference for the hemisphere with the thalamic lesion in most but not all patients. This asymmetry is clearer for the aESES group when leading-ICs are selected, (Fig. 4c). The iESES patients show an oppo- 
a) iESES
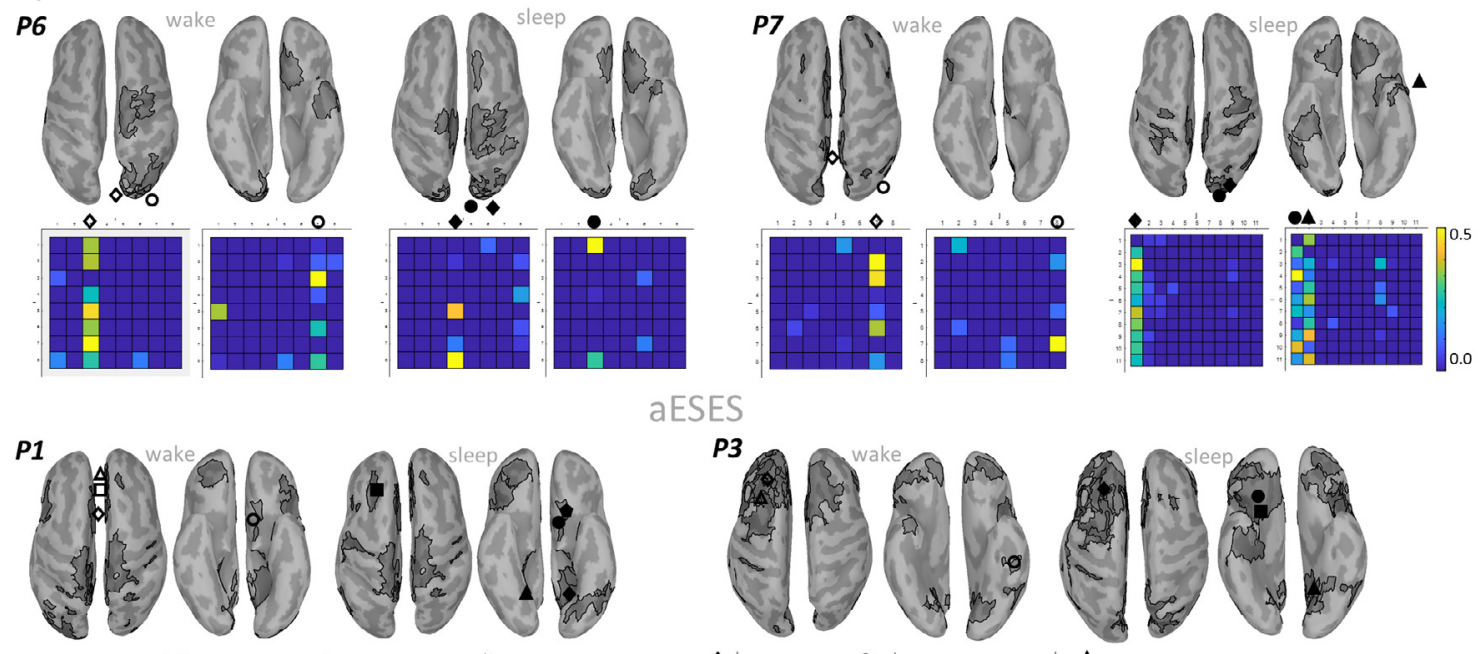

aESES
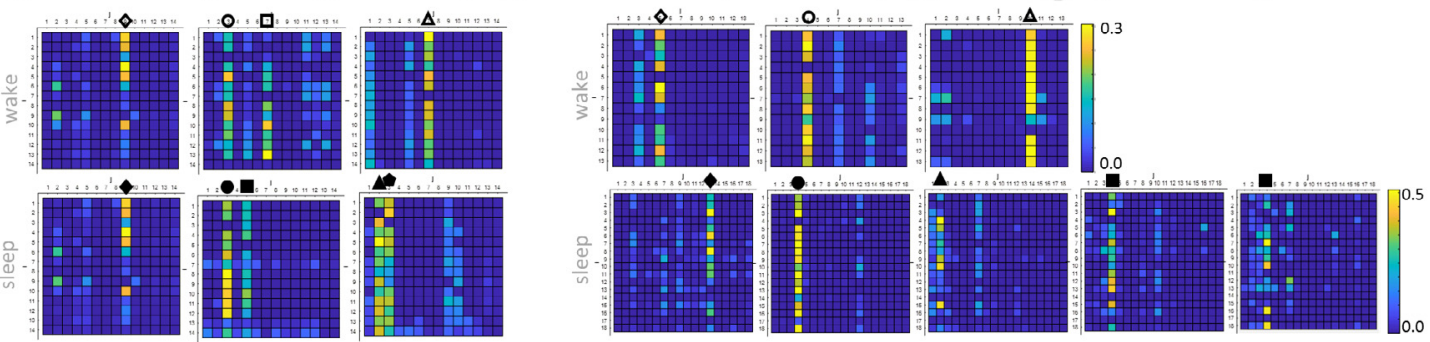

P2
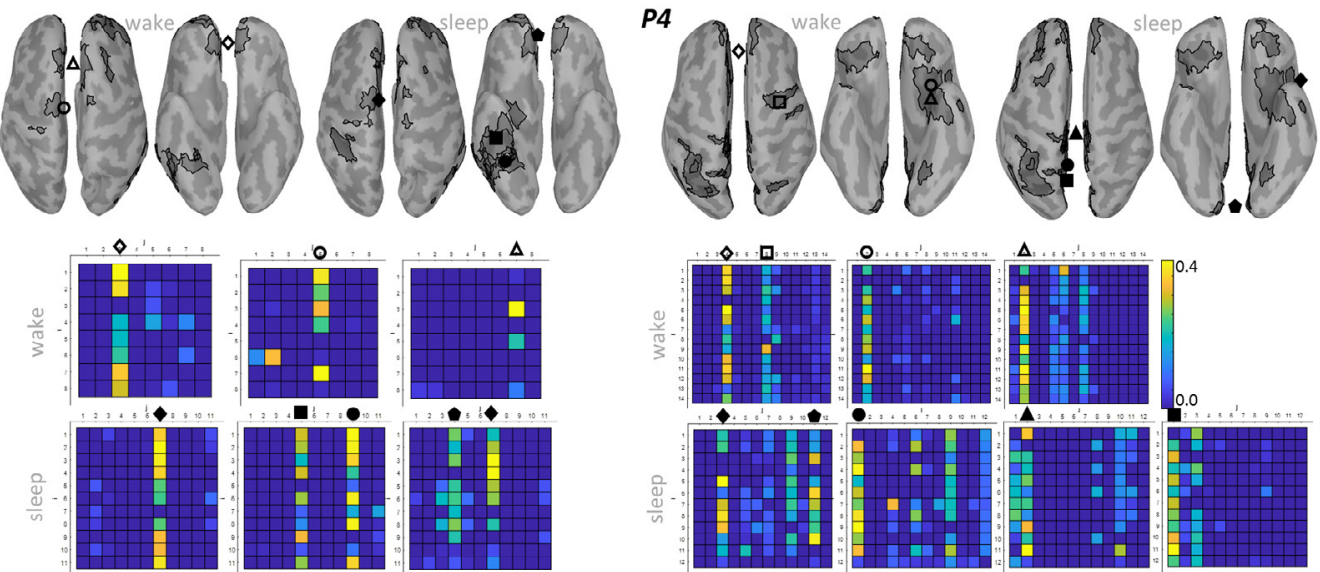

P5
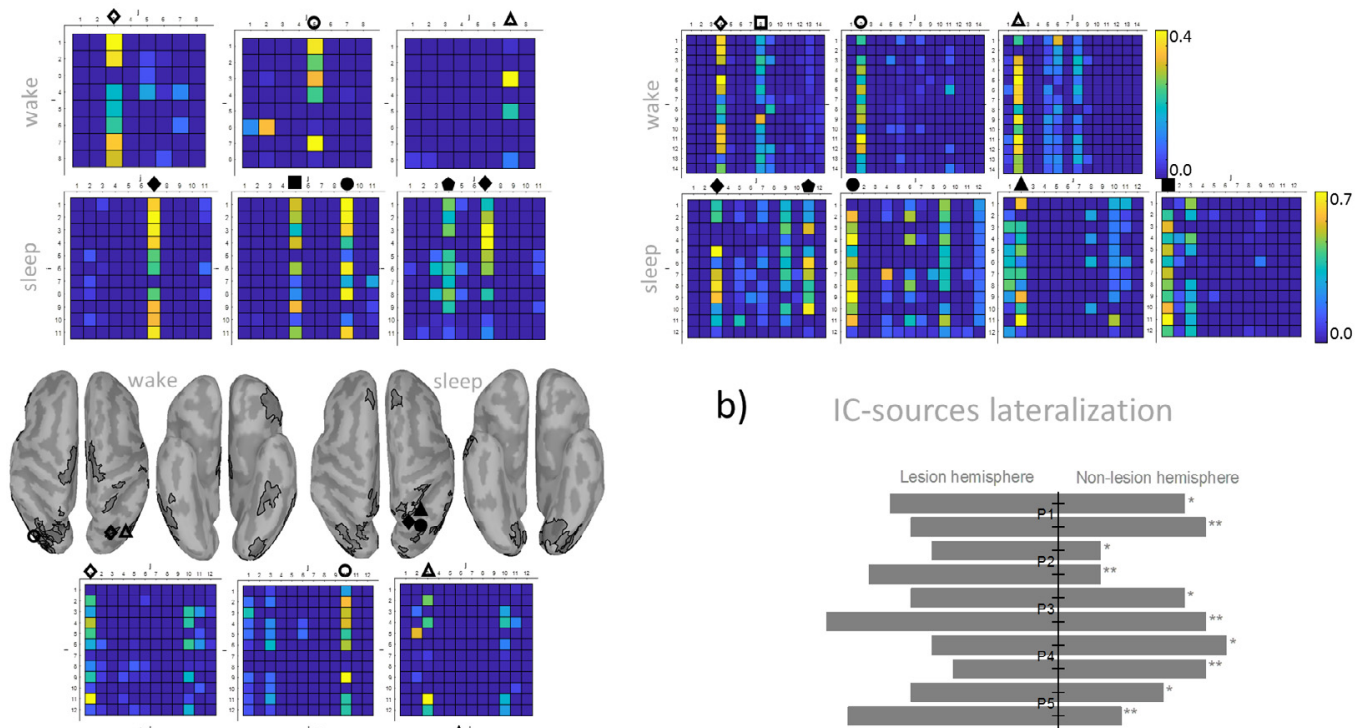

b)

IC-sources lateralization

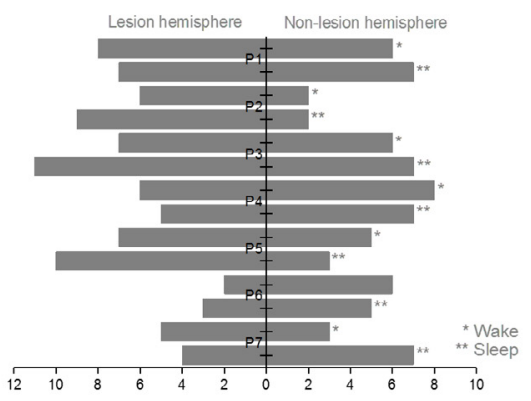

Fig. 3. (a) Cortical representation of spike-related-IC sources (dark grey) in wakefulness and sleep for the iESES and aESES groups, with ADTF connectivity matrix at the peak of source time courses (below). Dark blue are non-significant values $(\mathrm{p}<0.05)$ while other colors represent significant flow of information between spike-related-IC sources. Only a few spike-related ICs (labeled with symbol) act as outflow of information. (b) Spike-related-IC sources hemispheric lateralization with respect to thalamic lesion; IC Independent Component, ADTF -Adaptative Direct Transfer Function, iESES -inactive Encephalopathy with Status Epilepticus during slow Sleep, aESES - active Encephalopathy with Status Epilepticus during slow Sleep. 
a)

\section{aESES}

P1

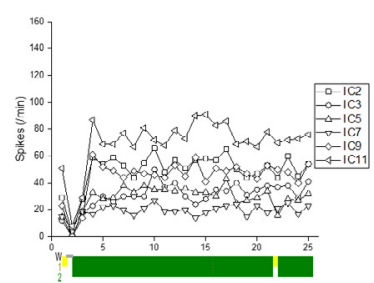

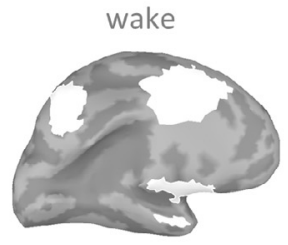
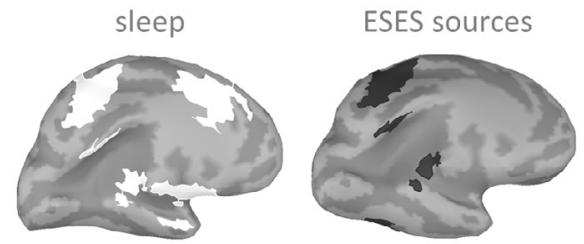

P2

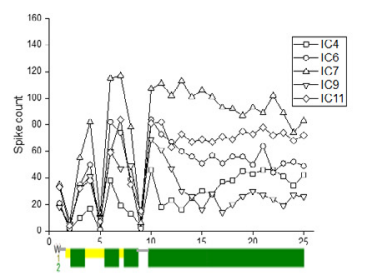

P3

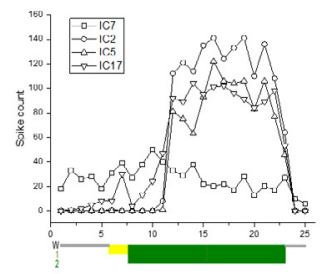

P4

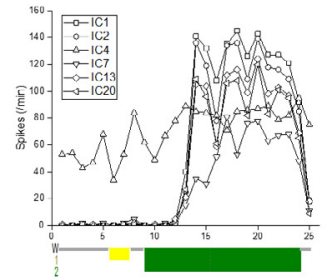

P5

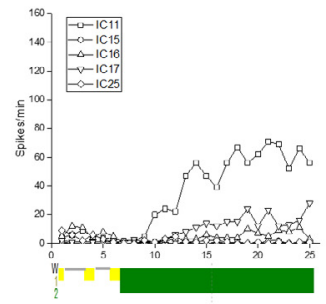

b)
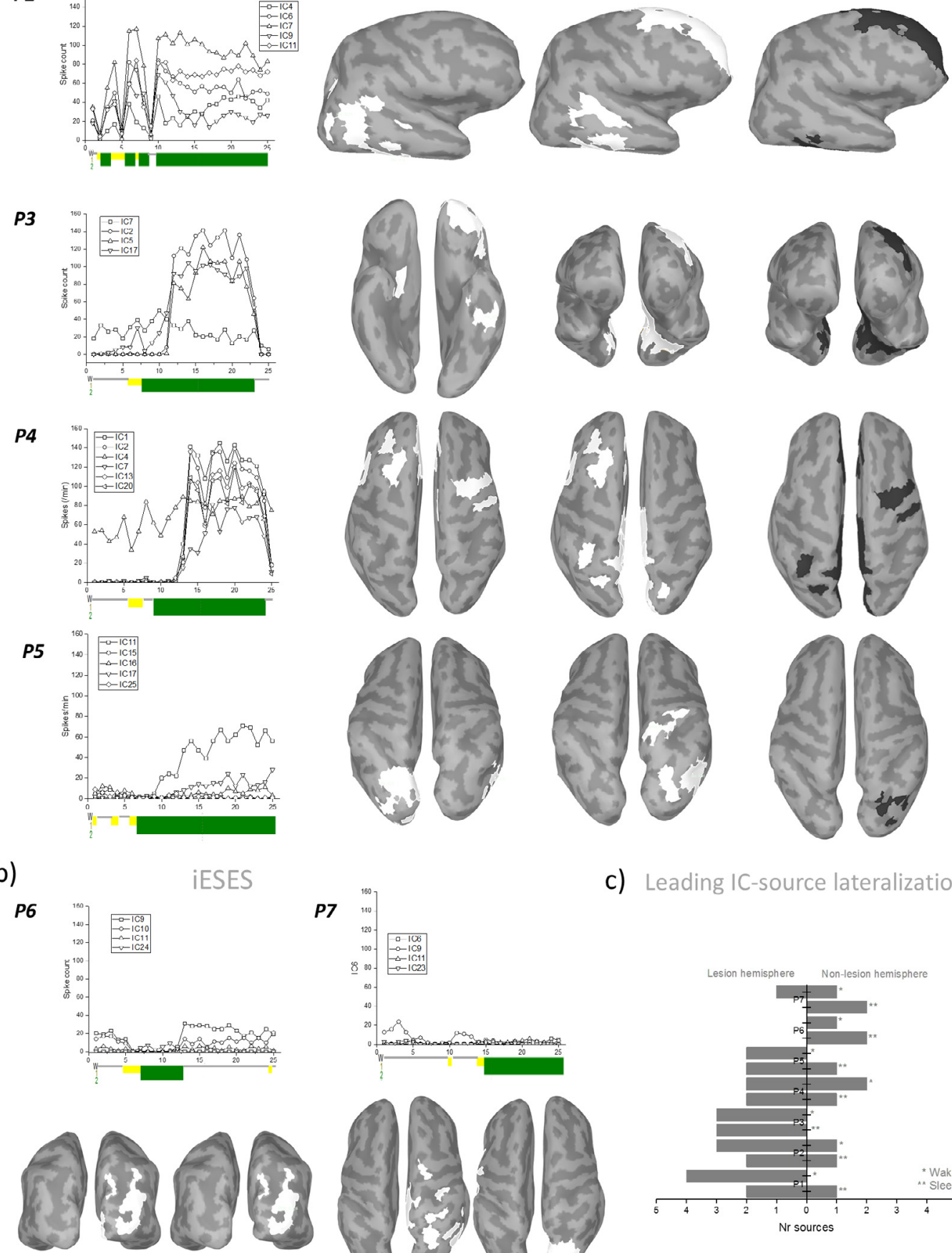

c) Leading IC-source lateralization

P7
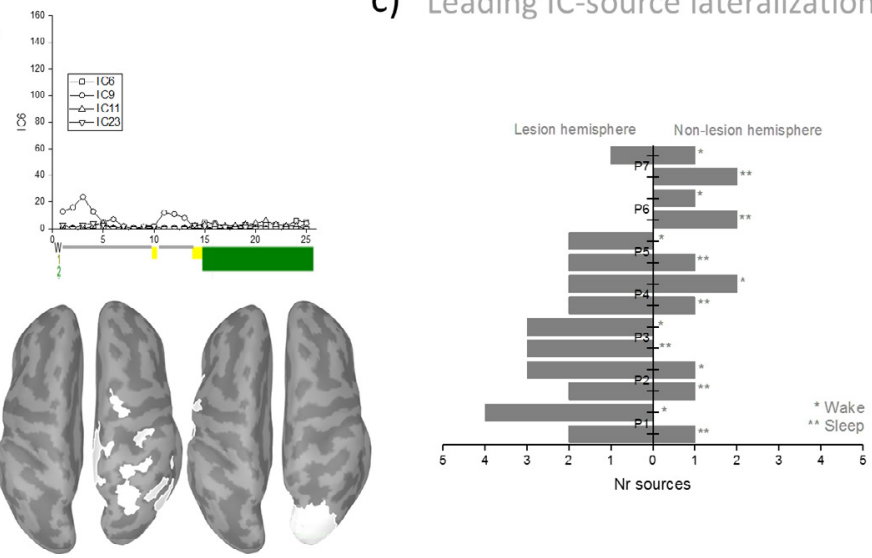

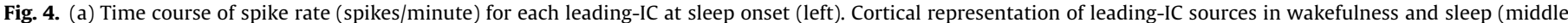

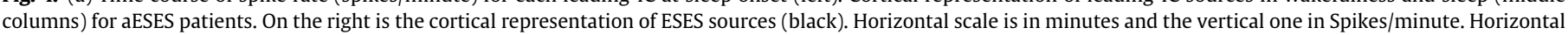

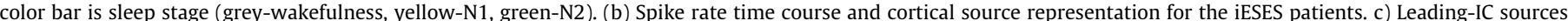

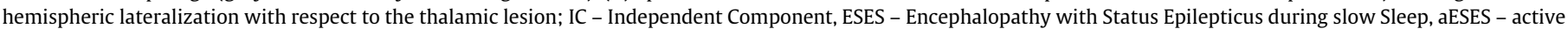
ESES, iESES - inactive ESES. 

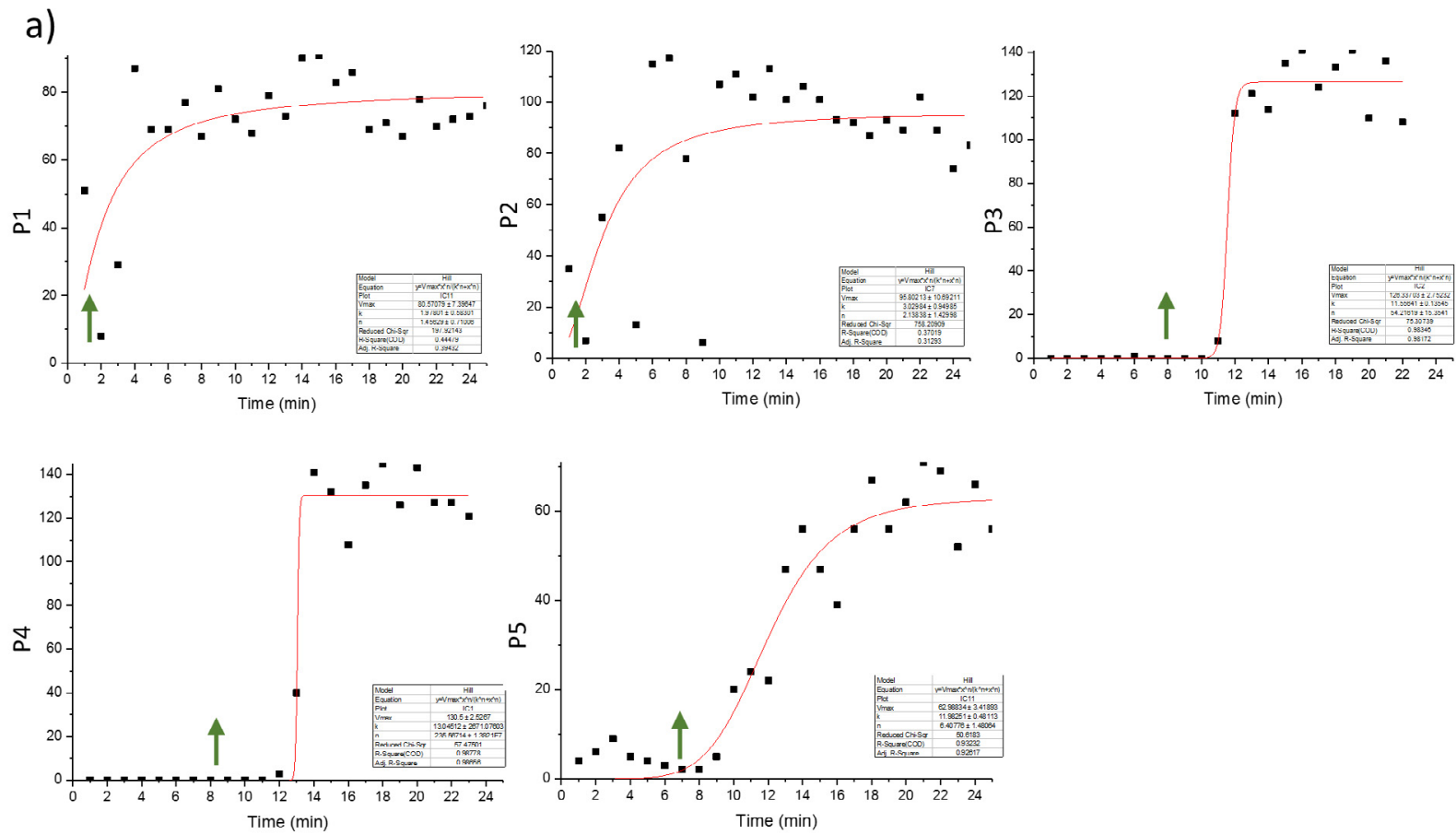

b)
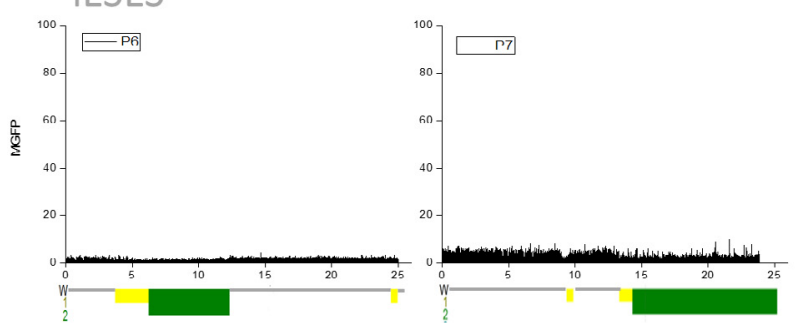

\section{aESES}
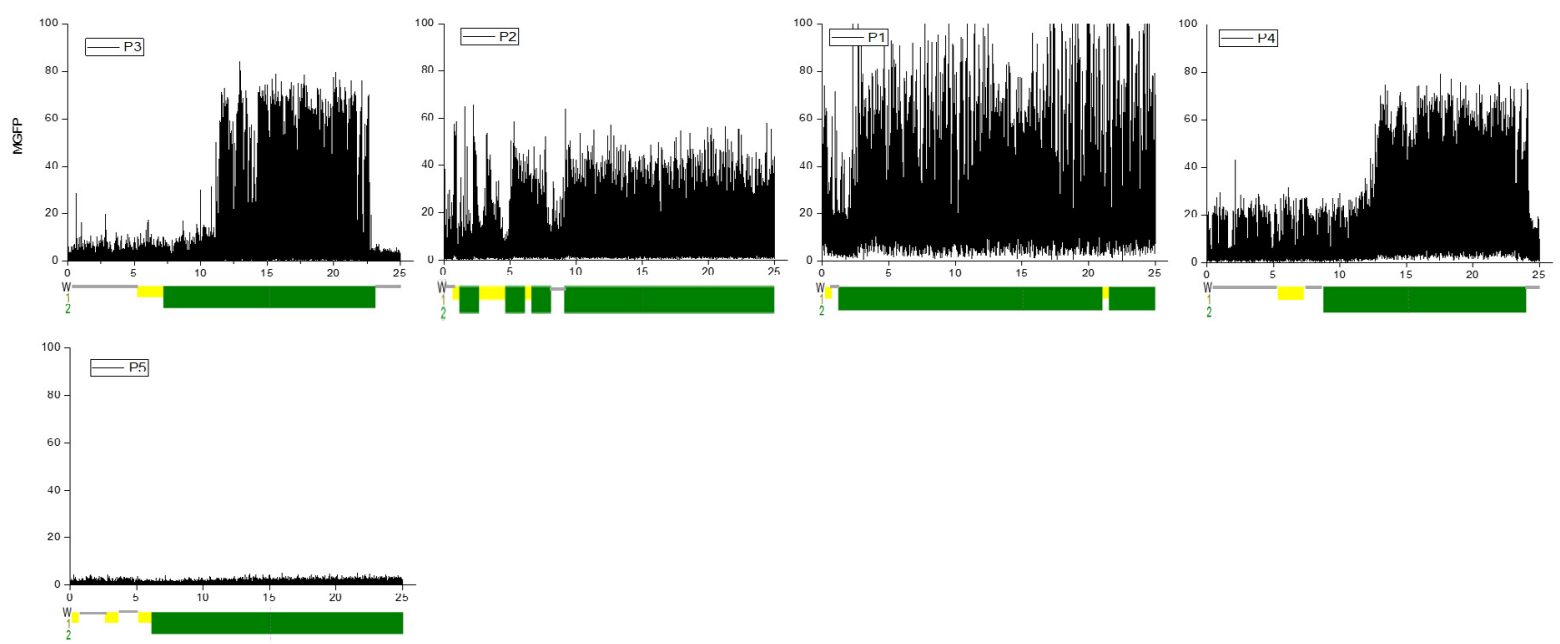

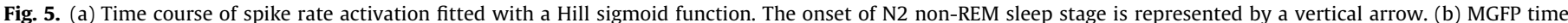

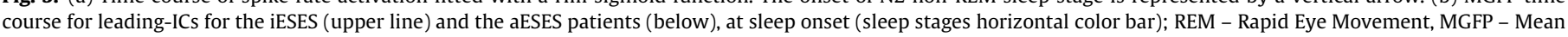

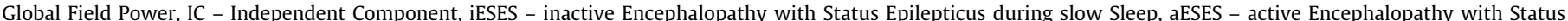
Epilepticus during slow Sleep.

site hemisphere dominance, but the localization near the occipital pole for both cases makes lateralization less reliable.

Overall, all patients demonstrate widespread and bihemispheric spike-related sources, which become less complex when information flow is considered. Both the iESES and the aESES patient P5 demonstrate simple patterns of leading-ICs, which allow identification of a single region of information outflow, stable from wakefulness to sleep. The remaining aESES patients present with 

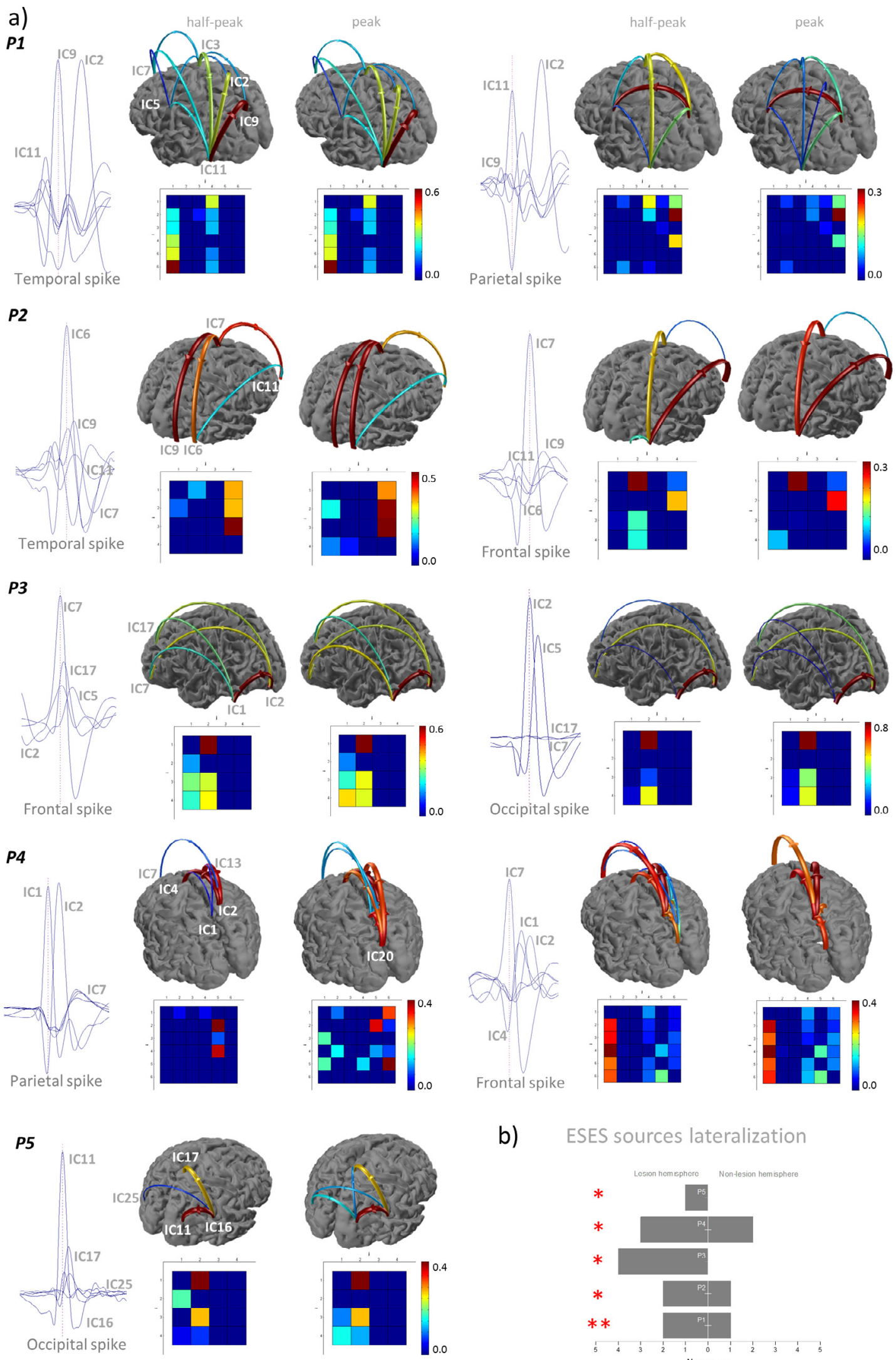

b)
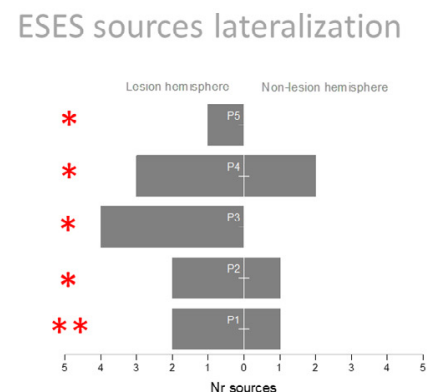

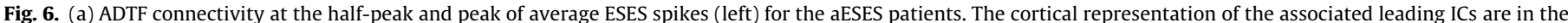

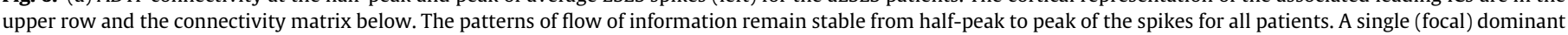

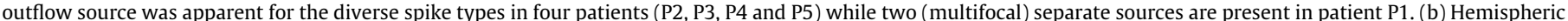

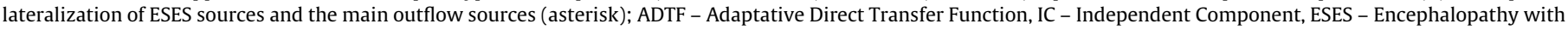
Status Epilepticus during slow Sleep, aESES - active ESES. 
more complex spatial patterns with sources distributing throughout both hemispheres with a slight dominance of the one with the thalamic lesion.

\subsection{Cortical sources of leading-ICS and ESES sources}

The spatial distribution of the leading-IC sources demonstrates a partial concordance between wakefulness and sleep, with a consistent trend for the sleep patterns to be more widespread in the aESES group, (Fig. 4a, middle columns). The quantification of spikes associated with each leading-IC at sleep onset puts in evidence that no sleep activation is present for the iESES, both in frequency (Fig. 4a, lower row) or power (Fig. 5b). In contrast, the aESES group demonstrates increase in both parameters of spike activity at sleep onset (ESES sources) in most but not all leading-ICs, (Fig. 4a, left), suggesting that not all cortical sources have the same sleep susceptibility. The distribution of non-contiguous ESES sources per hemisphere shows a clear asymmetry, with preference for the lesioned hemisphere, (Fig. 6b). Patient P5 shows intermediate results, with activation of a single ESES source at sleep onset, in frequency but not in power, which suggests an important but not complete therapeutic response to corticosteroids.

Overall, four of the five patients with aESES present with two (P1, P2 and P3) or three (P4) ESES sources localized in different lobes and activating significantly at sleep onset (Fig. 4a, right). Patient P5 shows a much-reduced activation of a single ESES source.

\subsection{Functional connectivity of ESES sources and number of independent generators}

In order to determine whether the different cortical areas activating at sleep onset in the aESES group are independent or result from secondary propagation, we classified the functional connectivity at half-peak and peak of average spikes from each area as focal or multifocal. In four (P2, P3, P4 and P5) of the five patients, the information flow for different spikes originated in a single (P2, P3 and P5) or in adjacent areas in the same lobe (P4), and were classified as focal ESES sources, (Fig. 6, row 2-5). Patient P1 showed independent outflow from temporal and parietal areas supporting ESES classification as multifocal ESES sources, (Fig. 6, row 1). In all patients the patterns of information flow at half-peak and peak of the average spikes were similar.

The analysis of the distribution per hemisphere demonstrates a complete lateralization of focal and multifocal ESES sources to the side of the thalamic lesion, (Fig. 6b, left).

Overall, in three of four aESES patients with apparently multifocal epileptogenic areas in sleep, we found evidence for a single generator with secondary propagation. One patient under corticosteroids had also a focal source. Only in one patient could we find evidence for multifocal generators in different lobes. All focal and multifocal ESES sources lateralized to the hemisphere with the thalamic lesion.

\subsection{Temporal spike activation and sleep stage}

For the five aESES patients the spike activation occurred shortly after the onset of N2 non-REM sleep stage, (Fig. 5a). The delay from the first epoch of $\mathrm{N} 2$ and the midpoint of the fitted sigmoid to the frequency time-course ranged from 1.5 to 5 minutes (average $3.3 \mathrm{~min}$ ). The onset of N1 non-REM sleep stage was not associated with any visible increase in spike frequency. In three patients which evolved from N2 to wakefulness a fast reduction to baseline was apparent (P2, P3 and P4).

Overall, the data supports a close temporal relation of spike activation with N2 non-REM sleep stage, both at onset and offset, while transition to $\mathrm{N} 1$ non-REM sleep stage does not produce any relevant change.

\section{Discussion}

The analysis of five patients with aESES put in evidence a significant activation of epileptic spikes at onset of N2 non-REM sleep stage, which in four cases originated in a single cortical area and only in one seems to originate in two independent regions. In all cases the activating cortex lateralized to the hemisphere with the unilateral thalamic lesion.

\subsection{Anatomical and clinical features}

Our series of ESES patients associated with early thalamic lesions has the same general features described by previous authors (Monteiro et al, 2001; Kelemen et al, 2006; Kersbergen et al, 2013; Van den Munckhof et al, 2020), with most patients expressing a significant recovery of developmental milestones after the neonatal illness, only to express a variable cognitive/behavioral regression following onset of epilepsy. All patients presented with thalamic lesions lateralized to one hemisphere, a circumstance that allowed the comparative analysis of both hemispheres in relation to the expression of the spike activity. In the patients of Losito et al., 2015 and in the syndrome of cortical polymicrogyria and thalamic hypoplasia (Bartolini et al., 2016), thalamic lesions also associated with ESES but the extensive cortical and subcortical lesions also present precluded the identification of the critical structural determinants of evolution to the syndrome. Other etiologies of ESES also express extensive cortical and subcortical lesions sometimes with preference for particular areas, such as the perisylvian region (Siniatchkin et al, 2010), without providing clues for a common underlying mechanism. The anatomically restricted ESES primary sources present in our study, in the absence of anatomical cortical lesions, strongly suggest that the appearance of ESES correlates with disruption of the normal anatomical-functional interaction of the lesioned thalamus and a restricted cortical area in the same hemisphere, without the need for cortical structural abnormalities.

Thalamic lesions associated with more extensive, mainly middle cerebral artery, strokes are much more common than isolated thalamic lesions (Losito et al., 2015) and there is some experience on the use of functional hemispherectomy for the treatment of the associated ESES (Battaglia et al, 2009; Kallay et al, 2009; Loddenkemper et al, 2009; Jeong et al, 2017). This disconnection procedure was strikingly effective in making the ESES disappear, suggesting that the cortex isolated from thalamic connections is not able to autonomously express spike activity with the ESES features. This observation, together with the demonstrated high probability of isolated neonatal thalamic lesions to evolve to ESES in the prospective study of (Van den Munckhof et al., 2020), supports a causal relationship between the two pathologies.

\subsection{EEG features in ESES}

A long-standing issue on the ESES literature has been the focal or generalized origin of spike activity (reviewed in Boer, 2009). Most evidence from ESES cases described in the literature support a predominance of focal or multifocal spikes in wakefulness that increase in abundance and become more diffuse in sleep, with little or no evidence for primarily generalized paroxysms (reviewed in Halász et al, 2014). Some cases with apparently generalized spike-wave proved on more detailed analysis to be due to secondary bilateral synchronization (Kobayashi et al, 1994), with interhemispheric delays compatible with transcallosal propaga- 
tion. The present results supporting a regional activation in the hemisphere with the thalamic lesion in the patients with aESES is in line with the previous evidence from the literature and with the electroclinical features of the associated partial epilepsies (Table 1 in Leal et al, 2018). We feel that these results are consistent despite the fundamental indetermination of the inverse problem in EEG. The use of realistic anatomical models of the head, a good spatial sampling of the EEG (82 channels) and an inverse method (sLORETA) with good localizing properties (Plummer et al, 2010) of the predominantly dipolar maps of ICs, ensemble should provide a spatial resolution at the sub-lobar level that is the basis of our inferences.

\subsection{Epileptic network analysis with EEG connectivity}

The demonstration of significant secondary propagation of spike activity (Kobayashi et al, 1994; Siniatchkin et al, 2010) is a significant obstacle to the identification of the primary sources of spikes that can benefit from the modeling of connectivity between the diverse generators (Wilke et al, 2008). The advantages of modelling network dynamics to unravel the origin of epileptic activity it is well established in epilepsy (Stefan and Lopes da Silva, 2013), and even less complex but apparently multifocal foci can benefit from the use of methods of connectivity analysis (Leal et al, 2013). The simplification obtained by excluding the epileptic generators without significant outflow of information it is a major contribution of the network connectivity analysis and promises to have a significant impact in the field of epileptology, where the identification of the primary epileptogenic areas is often clouded by a host of secondarily activated ones which overlap in the sensor space. The development of more robust methods to map the ESES spike activity such as the ones proposed in this paper could pave the way for more rational and targeted surgical disconnection procedures which could complement the functional hemispherectomies which have provided interesting results in the few cases operated (Kallay et al, 2009; Battaglia et al, 2009; Loddenkemper et al, 2009; Jeong et al, 2017).

\subsection{Cortical ESES sources and thalamic lesions}

The perisylvian regions have been repeatedly suggested to associate with ESES more often than other cortical areas (Siniatchkin et al, 2010; Halász et al, 2014), and well established ESES types such as the Landau-Klefner syndrome and the cortical polymicrogyria (Bartolini et al., 2016) show a clear functional or structural involvement of these cortical areas. Such suggestions must be tempered by the absence of an unbiased study of the cortical localization of ESES generators, the often-large dimensions of the cortical lesions and the frequent absence of well-established localization of ESES EEG generators in most studies published to date. In this context the ESES generators of our patients, (Fig. 6), demonstrate clearly non-perisylvian localizations over cortical association areas of the temporal (P1, P3 and P5), frontal (P2) and parietal (P1 and $\mathrm{P} 4)$ lobes of the hemisphere with the thalamic lesion. Because these areas are the main cortical target of medial thalamic nuclei (reviewed in Sherman, 2017), which are selectively lesioned in our patients, (Fig. 2), we consider that this anatomical correlation has a stronger potential to contribute to the ESES underlying mechanisms. In a previous study of largely the same group of patients a correlation was established between the relative volumetric loss of the Medio Dorsal and Pulvinar nuclei (the main medial nuclei), the white matter atrophy and the cortical distribution of spikes, suggesting that the details of the lesions in these nuclei have a determinant role in the cortical areas expressing the epileptic activity (Oliveira et al, 2020). A simple visual analysis of the MRIs of our patients (Fig. 2) puts in evidence ventricle enlargement on the hemisphere with the thalamic lesion, supporting a significant loss of white matter volume associated with the disruption of the thalamic-cortical connections.

\subsection{ESES sources activation and N2 non-REM sleep}

The temporal evolution of spike activity in relation with sleep onset puts in evidence a clear increase in relationship with the appearance of N2 non-REM sleep stage, which agrees well with the spectral analysis of Nobili et al (2001) demonstrating a strong increase in epileptiform discharges with the onset of sleep spindles. This has been used by Leal et al (2018) to propose that spindles can act as triggers of ESES spike activity in the cortical areas selectively disconnected from the dorsal thalamus. Furthermore, the spike activity reduced as fast as it appeared when spindles were suspended by awakening, giving additional support for the strong link between the two graphic elements.

\subsection{Limitations}

The study suffers from several limitations which can limit the reach of its conclusions:

a) The number of patients included was small, largely due to the strict inclusion criteria of ESES with structural lesions circumscribed to the thalamus. The number of active ESES at the time of study was further reduced because two of the patients had spontaneously recovered from the condition.

b) Some patients fell asleep shortly after onset of the recording, which allowed only for a small recording during wakefulness.

c) This is a transversal exploratory study which provides only an isolated assessment of spike dynamics at sleep onset per patient. Any variability in spike features along the natural history of ESES was not addressed.

\section{Declaration of Competing Interest}

The authors declare that they have no known competing financial interests or personal relationships that could have appeared to influence the work reported in this paper.

\section{References}

Bartolini Emanuele, Falchi Melania, Zellini Francesco, Parrini Elena, Grisotto Laura, Cosottini Mirco, et al. The syndrome of polymicrogyria, thalamic hypoplasia, and epilepsy with CSWS. Neurology 2016;86:1250-9. https://doi.org/10.1212/ WNL.0000000000002526.

Battaglia D, Veggiotti P, Lettori D, Tamburrini G, Tartaglione T, Graziano A, et al. Functional hemispherectomy in children with epilepsy and CSWS due to unilateral early brain injury including thalamus: Sudden recovery of CSWS. Epilepsy Res 2009;87:290-8.

Boer M. Guidelines for EEG in encephalopathy related to ESES/CSWS in children. Epilepsia 2009;50(Suppl 7):13-7.

Caraballo R, Fortini S, Flesler S, Pasteris M, Caramuta L, Portuondo E. Encephalopathy with status epilepticus during sleep: Unsual EEG patterns. Seizure 2015;25:117-25.

Caraballo R, Pavlidis E, Nikanorova M, Loddenkemper T. Encephalopathy with continuous spike-waves during slow-wave sleep: evolution and prognosis. Epileptic Disord 2019;21(Suppl 1):1-7.

Carvalho D, Mendes T, Dias A. Interictal spike quantification in continuos spikewave of sleep (CSWS): Clinical usefulness of a wearable EEG device. Epilepsy Behav 2020:104 106902.

Dorris L, O'Regan M, Wilson M, Zuberi S. Progressive intellectual impairment in children with Encephalopathy related to Status Epilepticus during slow Sleep. Epileptic Disord 2019;21(Suppl 1):S88-96.

Fernandez I, Takeoka M, Tas E, Peters J, Prabhu S, Stannard K, et al. Early thalamic lesions in patients with sleep-potentiated epileptiform activity. Neurology 2012;78:1721-7. 
Fischl B, van der Kouwe A, Destrieux C, Halgren E, Segonne E, Salat D, et al. Automatically parcellating the human cerebral cortex. Cereb Cortex 2004; $14: 11-22$.

Gramfort A, Papadopoulo T, Olivi E, Clerc M. OpenMEEG: opensource software for quasistatic bioelectromagnetics. BioMed Eng OnLine 2010;45:9.

Gibbs S, Nobili L, Haláz P. Interictal epileptiform discharges in sleep and the role of the thalamus in Encephalopathy related to Status Epilepticus during slow Sleep. Epileptic Disord 2019;21(Suppl 1):S54-61.

Halász P, Hegyi M, Siegler Z, Fogarasi A. Encephalopathy with Electrical Status Epilepticus in Slow Wave Sleep - a review with emphasis on regional (perisylvian) aspects. J Epileptol 2014;22:71-87.

He B, Dai Y, Astolfi L, Babiloni F, Yang L, Yuan H. eConnectome: A MATLAB toolbox for mapping and imaging of brain functional connectivity. J Neurosc Meth 2011;195:261-9.

Jeong A, Strahle J, Vellimana A, Limbrick D, Smyth M, Bertrand M. Hemispherotomy in children with electrical status epilepticus of sleep. J Neurosurg Pediatr 2017;19:56-62.

Kallay C, Mayor-Dubois C, Maeder-Ingvar M, Seeck M, Debatisse D, Deonna T, et al. Reversible acquired epileptic frontal syndrome and CSWS suppression in a child with congenital hemiparesis treated by hemispherectomy. Eur J Ped Neurol 2009; 13:430-8.

Kelemen A, Barsi P, Gyorsok Z, Sarac J, Szues A, Halasz P (2006) Thalamic lesion and epilepsy with generalized seizures, ESES and spike-wave paroxysms - Report of three cases. Seizure 15:454-458.733-740.

Kersbergen K, de Vries L, Leijten F, Braun K, Nievelstein R, Groenendaal F, et al. Neonatal thalamic hemorrhage is strongly associated with electrical status epilepticus in slow wave sleep. Epilepsia 2013;54(4).

Kobayashi K, Nishibayashi N, Ohtsuka Y, Oka E, Ohtahara S. Epilepsy with Electrical Status Epilepticus during Slow Sleep and secondary bilateral synchrony. Epilepsia 1994;35(5):1097-103.

Loddenkemper T, Cosmo G, Kotagal P, Haut J, Klaas P, Gupta A, et al. Epilepsy surgery in children with electrical status epilepticus in sleep. Neurosurgery 2009;64:328-37.

Leal A, Lopes R, Ferreira JC. Origin and Dynamics of epileptic activity in a symptomatic case of Panayiotopoulos syndrome: Correlation with clinical manifestations. Clin Neurophysiol 2013;124:20-6.

Leal A, Calado E, Vieira J, Mendonça C, Ferreira J, Ferreira H, et al. Anatomical and physiological basis of continuos spike-wave of sleep syndrome after early thalamic lesions. Epilepsy Behav 2018;78:243-55.

Losito E, Battaglia D, Chieffo D, Raponi M, Ranalli D, Contaldo I, et al. Sleeppotentiated epileptiform activity in early thalamic injuries: Study in a large series (60 cases). Epilepsy Res 2015;109:90-9.
Monteiro JP, Roulez-Perez E, Davidoff V, Deonna T. Primary neonatal thalamic haemorrhage and epilepsy with continuous spike-wave during sleep: a longitudinal follow-up of a possible significant relation. Eur J Pediatr Neurol 2001;5:41-7.

Nobili L, Baglietto M, Beelke M, de Carli F, de Negri E, Gaggero R, et al. Distribution of epileptiform discharges during nREM sleep in the CSWS syndrome: relationship with sigma and delta activities. Epilepsy Res 2001;44:119-28.

Oliveira A, Nunes R, Figueiredo P, Dias A, Leal A. Regional white matter atrophy correlates with spike activity in Encephalopathy related to Status Epilepticus during slow Sleep (ESES) after early thalamic lesions. Brain Topography 2020;33:571-85.

Pijn J, Vijn P, Lopes da Silva F, Boas V, Blanes W. The use of signal-analysis for the localization of an epileptogenic focus: a new approach. Adv Epileptology 1989;17:272-6.

Plummer C, Wagner M, Fuchs M, Vogrin S, Litewka L, Farish S, et al. Clinical utility of distributed source modeling of interictal scalp EEG in focal epilepsy. Clin Neurophysiol 2010;121:1726-39.

Sherman S. Functioning of circuits connecting thalamus and cortex. Compr Physiol 2017:7:713-39.

Siniatchkin M, Groening K, Moehring J, Moeller F, Boor R, Brodbeck V, et al. Neuronal networks in children with continuous spikes and waves during slow sleep. Brain 2010;133:2798-813.

Stefan H, Lopes da Silva F. Epileptic neuronal networks: methods of identification and clinical relevance. Front Neurol 2013;4:8.

Tadel F, Baillet S, Mosher J, Pantazis D, Leahy R. BrainStorm: A user-friendly application for MEG/EEG analysis. Comput Intell Neurosci. 2011:2011 879716.

Tassinari C, Dravet C, Roger J (1977) ESES: Encephalopathy related to Status Epilepticus during slow Sleep. In: Proceedings of the ninth congress International Federation of EEG and Clinical Neurophysiology. Amsterdam: Elsevier Science: 529-530.

Tassinari C, Rubboli G. Encephalopathy related to Status Epilepticus during slow Sleep: current concepts and future directions. Epileptic Disord 2019;21(Suppl 1):S82-7.

Van den Munckhof B, van Dee V, Sagi L, Caraballo R, Veggiotti P, Luikkonen E, et al. Treatment of electrical status epilepticus in sleep: A pooled analysis of 575 cases. Epilepsia 2015;56(11):1738-46.

Van den Munckhof B, Zwart A, Weeke L, Claessens N, Plate J, Leemans A, et al. Perinatal thalamic injury: MRI predictors of electrical status epilepticus in sleep and long-term neurodevelopment. Neuroimage Clin 2020;26 102227.

Wilke C, Ding L, He B. Estimation of time-varying connectivity patterns through the use of an adaptive directed transfer function. IEEE Trans Biomed Eng 2008;55 (11):2557-64. 